\title{
Removal of Basic Dye from Aqueous Medium Using Activated Carbon from Erythrina Brucei, Arundinaria Alpina and Manihot Esculenta
}

\author{
Sisay Tadesse* Demeke Ambo \\ Hawassa University, College of Natural and Computational Sciences, Department of Chemistry, P.O.Box 05, \\ Hawassa, Ethiopia
}

\begin{abstract}
This work deals with the preparation of activated carbon (AC) from Korch (Erythrina brucei) sawdust (EB), Bamboo (Arundinaria alpina) sawdust (AA), and Cassava peel (Manihot esculenta) powder (ME) to remove methylene blue (MB) from aqueous solution. The effect of temperature, chemical impregnation $\left(\mathrm{H}_{3} \mathrm{PO}_{4}, \mathrm{ZnCl}_{2}\right.$, $\mathrm{KOH}$ and $\mathrm{H}_{2} \mathrm{SO}_{4}$ ) were done. The optimum temperature used to prepare activated carbon of EB, AA and ME were $700^{\circ} \mathrm{C}, 400^{\circ} \mathrm{C}$ and $600^{\circ} \mathrm{C}$ respectively. High surface area $\mathrm{AC}$ was obtained by chemical activation of biomaterial with $\mathrm{H}_{3} \mathrm{PO}_{4}$. The effect of various process parameters like $\mathrm{pH}$, contact time, adsorbent dose on the efficiency MB removal was investigated. The optimum $\mathrm{pH}$ value and contact time for $\mathrm{AC}$ of $\mathrm{EB}$, AA and ME was determined as 6, 5, 4 and 40,50,60 min respectively. The optimum adsorbent dose of EB, AA and ME were determined $0.04,0.06$ and $0.12 \mathrm{~g}$ respectively in $25 \mathrm{ml}$ of solution. Thermodynamic analysis asserted endothermic and spontaneous nature of the system. Equilibrium data were represented better by Langmuir model than Freundlich which describes monolayer adsorption. The linear regression analysis of kinetic data confirmed that Pseudo-second order rate expression.
\end{abstract}

Keywords: activated carbon, E. brucei, A. alpina, M. esculenta, methylene blue.

DOI: $10.7176 / \mathrm{FSQM} / 86-03$

Publication date: April $30^{\text {th }} 2019$

\section{Introduction}

Liquid waste effluents released from textiles, cosmetics, printing, dying, food processing and paper making industries contains many different organic pollutant dyes. Discharge of these colored pollutants presents a major environmental problem because of their toxic and carcinogenic effects on living organisms (Acemioglu, B. 2004). Textile wastewater is characterized by high chemical oxygen demand, low biodegradability and high salt content and is a source of pollution related to color. In addition, colored compounds (dyes and pigments) discharged from several industries are very harmful to aquatic life in rivers and lakes. The treatment method selected for these organic pollutants will depend primarily on the pollutant concentration, the effluent flow and the discharge body. Synthetic dyes present high solubility and low biodegradability. For these reasons, conventional physiochemical techniques are not suitable for synthetic dye removal. Therefore, adsorption may be employed for the treatment of synthetic dye waste (Abdelwahab, O., et al.2006, El-Sikaily et al.2006, Ho, Y.S. et al.2005, Ozacar, M. and Engil, $I^{\top}$.A. S. 2005, Akkaya, G. et al.2007). Adsorption has significant advantages: low operating cost, high flexibility, simple design and operation, easy automation, and the capability to operate at a very low concentration (Cooper, P. (1995).

Adsorption processes using activated carbon are widely used to remove pollutants from wastewater. However, commercially available AC is expensive. Special emphasis on the preparation of AC from several agricultural byproducts has been given due to the growing interest in low cost AC from renewable, abundant, especially for application concerning treatment of wastewater. Researchers have studied the production of AC from orange peel (Pandiarajan, A.,et al., 2018), rice husks (Rahman, I.A., et al., 2005), bagasse (Thuan, T. V., et al., 2016), palmtree cobs (Avom, J. et al., 1997). The advantage of using agricultural by-products as raw materials for manufacturing $\mathrm{AC}$ is that these raw materials are renewable and potentially less expensive to manufacture. Plant biomass is a natural renewable resource that can be converted into useful materials and energy (Girgis, B.S, et al., 2008).

Plant resources and Agricultural wastes are currently receiving attention as raw materials for water pollution control because of their availability and low-cost. In this context, we are investigating the potential of the AC obtained from sawdust of EB, and AA and peel powder of ME, which are considered as agricultural solid waste, as an alternative low-cost dye adsorbent. To make better use of these cheap and abundant agricultural wastes, it is proposed to use it as an adsorbent after converting into $\mathrm{AC}$ to remove basic dye from aqueous solutions. Thus, the purpose of the present work was to investigate the optimum experimental condition for the preparation of the most efficient AC from saw dust of EB and AA, and peel powder of ME and use it for the removal of methylene blue from aqueous solutions. The second objective was to investigate the ability of two isotherms models; namely the Langmuir and the Freundlich adsorption isotherms, to model the equilibrium adsorption data. Finally, kinetic and 
thermodynamic studies have been conducted and the rate of MB adsorption on the prepared AC was determined.

\section{Materials and Methods}

\subsection{Preparation of activated carbon:}

The sample materials for this study are ME Peel, EB and AA saw dust. ME peel is obtained from local farm. EB and AA saw dust are obtained from local carpenter. They were initially washed with hot distilled water several times, dried in oven( Digit heat, J. P. Selecta, Spain) and stored in sealed plastic bags for further experiments. The ME Peel were ground with diameters of approximately $1.0 \mathrm{~mm}$, washed with hot distilled water several times, dried in oven at $100{ }^{\circ} \mathrm{C}$ for 24 hours and stored in sealed plastic bags for further experiments.

The biomaterials of EB, ME and AA powder samples were weighed on a digital analytical balance (ADAM, model AFP-110L,ENGLAND). The powder was soaked in $98 \% \mathrm{H}_{2} \mathrm{SO}_{4}$ (LOBA. CHEMIE) $85 \% \mathrm{H}_{3} \mathrm{PO}_{4}$ (MUMBI 30 ), $\mathrm{KOH}$ (centeral drug house of (P) Ltd. INDIA ) and $\mathrm{ZnCl}_{2}$ (NICE) solution for 24 hours followed by decantation and repeated washing of the modified biomaterials using distilled water to make it free of activating agents until the $\mathrm{pH}$ of the supernatant solutions remain neutral or free of chloride ion and dried overnight at 100 ${ }^{0} \mathrm{C}$ in a Drying oven (Digit heat, J. P. Selecta, Spain). Then AC of AA, ME and EB powder were subjected to carbonization at different temperature from $400{ }^{\circ} \mathrm{C}$ to $800{ }^{\circ} \mathrm{C}$ in an electric furnace (Carbolite, England) for 2 hours. After completing the carbonization process it was cooled in desiccators, crushed and sieved to desired mesh size $250 \mu \mathrm{m}$ to eliminate the effect of sieve size in the study and stored in a glass bottles. MB (NICE) used for characterization of the prepared $\mathrm{AC}$ and also used as adsorbate for this study.

\subsection{Effect of Impregnation Chemicals:}

The effect of impregnation of different chemical agents such as sulfuric acid $\left(\mathrm{H}_{2} \mathrm{SO}_{4}\right)$, phosphoric acid $\left(\mathrm{H}_{3} \mathrm{PO}_{4}\right)$, zinc chloride $\left(\mathrm{ZnCl}_{2}\right)$ and potassium hydroxide $(\mathrm{KOH})$ on the porous characteristics was studied. $1 \mathrm{~g}$ of each of the biomaterials were impregnated in $2 \mathrm{~mL}$ of $\mathrm{H}_{2} \mathrm{SO}_{4}, \mathrm{H}_{3} \mathrm{PO}_{4}, \mathrm{ZnCl}_{2}$ and $\mathrm{KOH}$ and after thorough the activated biomaterials were washed to remove excess chemicals and to neutralize and dried in drying oven at $100{ }^{\circ} \mathrm{C}$. The dried activated biomaterials are carbonized at $400{ }^{\circ} \mathrm{C}, 500{ }^{\circ} \mathrm{C}, 600{ }^{\circ} \mathrm{C}, 700{ }^{\circ} \mathrm{C}$ and $800{ }^{\circ} \mathrm{C}$ for each of bio materials to prepare the respective activated carbon (Hashemian, S., et al., 2014).

\subsection{Effect of Carbonization Temperature:}

Carbonization temperature is one of the most influencing factors for development of porosity during activation process (Ioannidou, O. and Zabaniotou, A.,2017). Effect of carbonization temperature on porous characteristics of developed $\mathrm{AC}$ was investigated in the range of $400-800{ }^{\circ} \mathrm{C}$. The optimum carbonization temperature varied with the type of biomaterials used for producing activated carbon (Hashemian, S., et al., 2014).

2.4. Batch adsorption study using AC prepared at optimum experimental conditions:

\subsubsection{Effect of Absorbent doses}

The adsorption of Methylene blue by AC of EB, ME, and AA were investigated using the following adsorbent doses $0.01,0.02,0.04,0.06,0.08,0.1$ and $0.12 \mathrm{~g}$ in $25 \mathrm{~mL}$ of $5 \mathrm{ppm} \mathrm{MB}$ by keeping other Variables constant (at optimum contact time and temperature). After time was completed the adsorbents were centrifuged and removed from the solution and the concentration of residual MB in each solution was determined using UV-Vis-NIR spectrophotometer (Perkin-Elmer Lambda series/UVCSS).

\subsubsection{Effect of Contact Time}

The effect of contact time on removal of MB was studied taking $0.04 \mathrm{~g}, 0.06 \mathrm{~g}$ and $0.12 \mathrm{~g}$ of AC of EB, AA and $\mathrm{ME}$ respectively and was added to different conical flasks containing $25 \mathrm{~mL}$ of $5 \mathrm{ppm} \mathrm{MB}$ solution. The flask was closed and placed onto a laboratory shaker for each of different contact times chosen $(15,30,45,60,75$, and 90, 105 and 120 minutes). The content of flask was filtered and concentration of the residual MB was determined using UV-Vis-NIR spectrophotometer.

2.4.3. Effect of $\mathrm{pH}$

The effect of $\mathrm{pH}$ on the $\mathrm{MB}$ adsorptions onto $\mathrm{AC}$ of $\mathrm{EB}, \mathrm{AA}$ and $\mathrm{ME}$ was studied at $\mathrm{pH}$ range of 2.0 to 10.0 using portable $\mathrm{pH}$ meter (Model H1924, HANNA Instrument). For this study $25 \mathrm{~mL}$ of MB solution with initial concentration of $5 \mathrm{ppm}$ was taken in $50 \mathrm{~mL}$ Erlenmeyer flasks and $\mathrm{pH}$ was adjusted to $\mathrm{pH}$ of 2.0-10.0 using required quantity of $1 \mathrm{~N} \mathrm{HCl}$ or $1 \mathrm{~N} \mathrm{NaOH}$ before mixing the adsorbent. Then $0.04 \mathrm{~g}, 0.06 \mathrm{~g}$ and $0.12 \mathrm{~g}$ of $\mathrm{AC}$ of $\mathrm{EB}, \mathrm{AA}$ and $\mathrm{ME}$ respectively was added to the solutions and placed onto a laboratory shaker at room temperature and optimum time. The content of flask was filtered and concentration of residual MB was determined using UVVis-NIR spectrophotometer.

\subsection{Isotherm study}

Equilibrium isotherms were studied by taking $25 \mathrm{~mL}$ of MB solutions of (10 ppm, $15 \mathrm{ppm}, 20 \mathrm{ppm}, 30 \mathrm{ppm}, 40$ ppm, $50 \mathrm{ppm}, 80 \mathrm{ppm}$ and $100 \mathrm{ppm}$ ) in $50 \mathrm{ml}$ Erlenmeyer flask. Then $0.04 \mathrm{~g}, 0.06 \mathrm{~g}$ and $0.12 \mathrm{~g}$ of AC of EB, AA 
and ME was added respectively to solution and shaken in a laboratory shaker. The content of flask was filtered and concentration of MB in the solution was determined using UV-Vis-NIR spectrophotometer. To establish adsorption capacity of adsorbents, experimental data was fitted against Langmuir and Freundlich isotherm equations (Ratan, J. K., et al., 2018).

\subsection{Kinetic study}

Kinetic study was conducting by taking $25 \mathrm{~mL}$ of MB solution of with initial concentration of $10 \mathrm{ppm}$ and $15 \mathrm{ppm}$ in $50 \mathrm{ml}$ Erlenmeyer flasks. Then $0.04 \mathrm{~g}, 0.06 \mathrm{~g}$ and $0.12 \mathrm{~g}$ of $\mathrm{AC}$ of EB, AA and ME was added respectively to the solutions. The solutions were sampled at a time interval of $(10,20,30,45,60,75,90,120,150$ and 180 minutes) and the concentrations of the filtrates were analyzed by UV-Vis-NIR spectrophotometer. Experimental data was analyzed against kinetic models, which explain the mechanism of the adsorption processes. The kinetics adsorption on AC of EB, AA and ME were analyzed using Pseudo first-order and pseudo second-order kinetic models (Mokri, H. S. G., et al. 2015).

\subsection{Thermodynamic study}

Thermodynamic study was conducted by taking $25 \mathrm{~mL}$ of MB solutions with initial concentrations of $10 \mathrm{ppm}$ and $15 \mathrm{ppm}$ in $50 \mathrm{ml}$ Erlenmeyer flasks. Then $0.04 \mathrm{~g}, 0.06 \mathrm{~g}$ and $0.12 \mathrm{~g}$ of $\mathrm{AC}$ of EB, AA and ME was added respectively to the solutions. Solution was shaken at different temperature $\left(20{ }^{\circ} \mathrm{C}, 30{ }^{\circ} \mathrm{C}, 40{ }^{\circ} \mathrm{C}, 50{ }^{\circ} \mathrm{C}\right.$ and $\left.60{ }^{\circ} \mathrm{C}\right)$ and the content of flasks were filtered and concentration of $\mathrm{MB}$ was determined using UV-Vis-NIR spectrophotometer.

\section{Results and Discussion}

\subsection{Optimization of carbonization temperature and impregnation chemicals}

The effect of carbonization on the adsorption capacity of AC is shown in Figure 1(i). With the increase temperature from 400 to $700{ }^{\circ} \mathrm{C}$, the adsorption capacity (\% Removal efficiency) of AC of EB were increased and reach at maximum $700{ }^{\circ} \mathrm{C}$ then decreased up on further increase in temperature. For AC of AA the maximum adsorption was at $400{ }^{\circ} \mathrm{C}$ and decreased up on further increasing in temperature and the adsorption capacity of $\mathrm{AC}$ of $\mathrm{ME}$ were increased from 400 to $600{ }^{\circ} \mathrm{C}$ then decreased randomly up on increasing temperature beyond $600{ }^{\circ} \mathrm{C}$. The decrease in adsorption capacity of $\mathrm{AC}$ at higher temperature values can be because of the collapsed pore volume and surface areas or the loss of $\mathrm{AC}$ at higher temperature. From Figure 1 we can see that the optimum carbonization temperature of activated carbon of $\mathrm{EB}, \mathrm{AA}$ and $\mathrm{ME}$ were $700{ }^{\circ} \mathrm{C}, 400{ }^{\circ} \mathrm{C}$ and $600{ }^{\circ} \mathrm{C}$ respectively.

The effect of impregnation chemicals on performance of microporus ACs are shown in Figure 1(ii). In all cases the adsorption capacity of the prepared $\mathrm{AC}$ of EB, AA and ME produced by the impregnation of $\mathrm{H}_{3} \mathrm{PO}_{4}$ gave the maximum adsorption capacity.
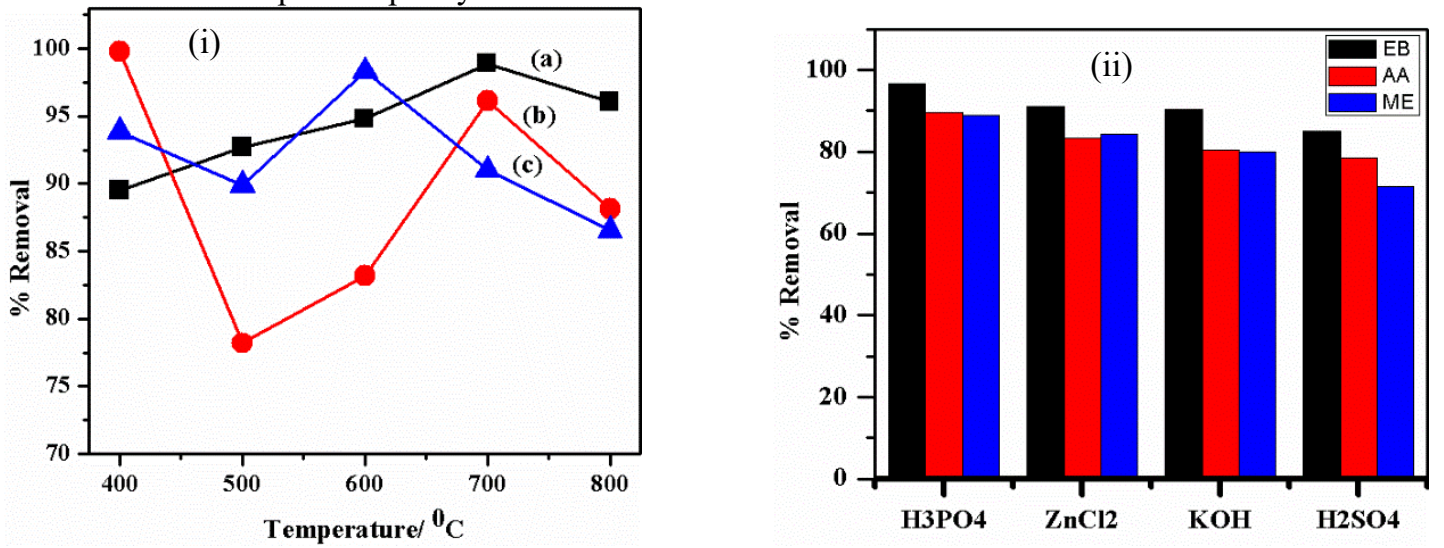

Figure 1. Optimization of preparation condition of AC. (i)The Effect of carbonization Temperature on preparation of AC from (a) EB, (b) AA and (c) ME. (ii) Effect of activating reagents on preparation of activated carbon.

\subsection{Determination of $\mathrm{pH}$ point of zero charge ( $\mathrm{pHpzc}$ )}

The surface chemistry of any material is determined by the acidic or basic character of their surface. It is very important to know the surface charge of the materials in the aqueous media, especially in adsorption studies. We may produce high surface area material but if the surface charge of the material is opposing the adsorption because of having the same charge as the adsorbate, reduces the adsorption capacity. Therefore we have to modify and find the $\mathrm{pH}$ conditions for efficient adsorption. We also need to find out the $\mathrm{pH}$ at which the surface charge of the materials is zero in the aqueous solution, the $\mathrm{pH}_{\mathrm{pzc}}$ of the adsorbent material. $\mathrm{pH}_{\mathrm{pzc}}$ value at optimized operational 
parameter are 7.3, 5.6 and 4.3 for AC obtained from EB, AA and ME respectively (Figure 2). Net surface charge of the $\mathrm{AC}$ below $\mathrm{pH}_{\mathrm{pzc}}$ is positive and it is negative above $\mathrm{pH}_{\mathrm{pzc}}$.

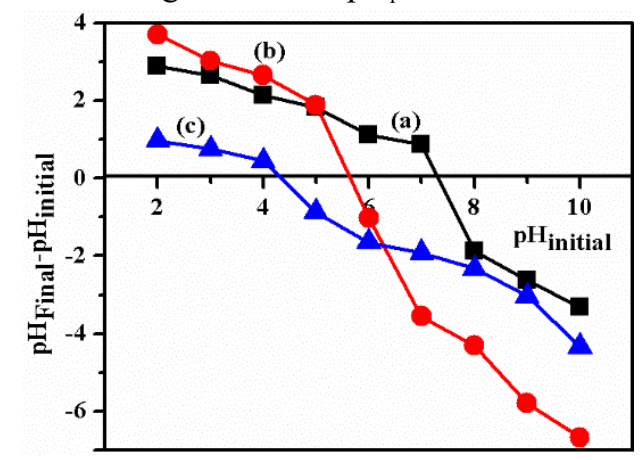

Figure 2. The pH on point zero charge of ACs of (a) EB, (b) AA, and (c) ME

\subsection{Batch adsorption study: Effect of Adsorbent Dose and contact time}

The effect of adsorbent dose on the efficiency of MB removal using AC of EB, AA, and ME can be viewed in Figure 3(i), The removal efficiency MB by AC of EB, AA, and ME increased from $84.9 \%$ to $99.55 \%, 96.07 \%$ to $98.33 \%$ and $75 \%$ to $91 \%$ respectively with increasing doses of the AC from $0.01 \mathrm{~g}$ to $0.12 \mathrm{~g}$ per $25 \mathrm{~mL}$ solution at a fixed MB concentration of $5 \mathrm{ppm}$. This can be attributed to an increased adsorbent surface area and availability of more adsorption sites resulting from the increased adsorbent dosage. With further rise in the adsorbent dosage, the adsorption capacity decreased. The amount of dye adsorbed per unit mass of adsorbent decreased with further increasing adsorbent mass, due to the reduction in effective surface area. Similar behavior for the effect of adsorbent concentrations on MB adsorption capacity was observed and discussed in the literature for other types of adsorbents (Vadivelan, V. and Kumar, K.V, 2005, Han, R., et al., 2006, Ncibi, M.C., et al.,2007).

In order to find out the time for equilibrium adsorption, the contact time for $\mathrm{MB}$ on the $\mathrm{EB}, \mathrm{AA}$ and ME were varied from $5 \mathrm{~min}$ to $120 \mathrm{~min}$ at a fixed MB concentration of $5 \mathrm{ppm}$, a dosage of $0.04 \mathrm{~g}, 0.06 \mathrm{~g}$ and $0.12 \mathrm{~g}$ per 25 $\mathrm{ml}$ solution respectively, at $20{ }^{\circ} \mathrm{C}$. At initial stage, the adsorption curve rises sharply with time indicating that the rate adsorption of $\mathrm{MB}$ is quite high and there are plenty of readily accessible sites. The adsorption reaches at maximum, $98.51 \%, 99.34 \%$ and $97.16 \%$ for activated of EB, AA and ME at 40, 50 and 60 min respectively (Figure 3(ii)). Hence the optimum contact time was selected for activated carbon of EB, AA and ME as 40, 50 and 60 min respectively for further experiments.
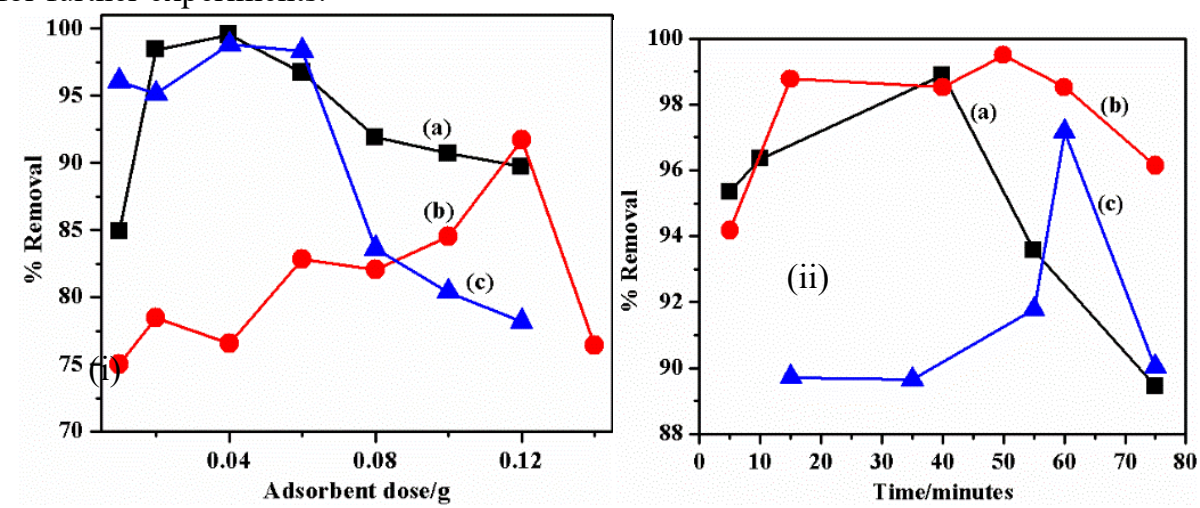

Figure 3. Batch adsorption study (i) Optimization of Dose of adsorbents from (a) EB, (b) ME and (c) AA (ii)

\subsubsection{Effect of $\mathrm{pH}$}

Effect of contact time on preparation of ACs of (a) EB, (b) AA, (c) ME

The effect of $\mathrm{pH}$ on adsorption of $\mathrm{MB}$ on $\mathrm{AC}$ was examined in the $\mathrm{pH}$ range of 2-10. Figure 4 depicts the effect of $\mathrm{pH}$ on adsorption of MB. AC of EB showed maximum adsorption at $\mathrm{pH} 6(99.42 \%)$ and it decreases at higher and lower than this value. Whereas AC of AA showed maximum adsorption at pH $5(97.37 \%)$ and it also decreases at higher and lower than this value and for $\mathrm{AC}$ of $\mathrm{ME}$ the maximum adsorption was observed at $\mathrm{pH} 4(99.13 \%)$ and similar to EB and AA it decreases at higher and lower than this value. These values indicate that the activated carbon of $\mathrm{EB}, \mathrm{AA}$ and $\mathrm{ME}$ are applicable for the removal of $\mathrm{MB}$ from aqueous solution under acidic environment. 


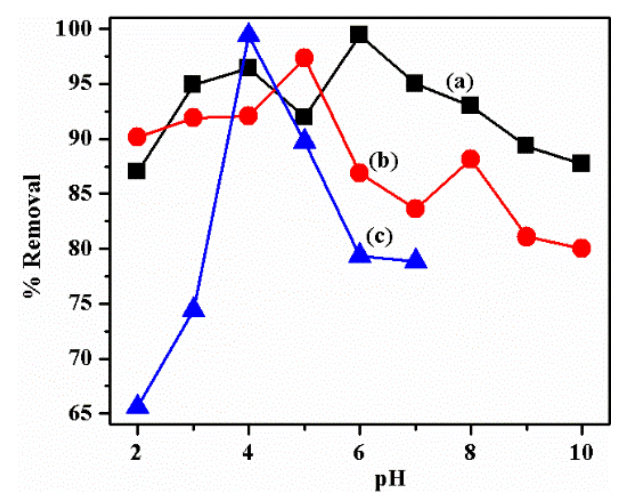

Figure 4. Effect of $\mathrm{pH}$ on the preparation of ACs of (a) EB, (b) AA, (c) ME

\subsection{Adsorption Thermodynamic study}

Thermodynamic parameter that help us to understand the nature of adsorption of Methylene blue on adsorbents are the standard change in Gibbs free energy $\left(\Delta \mathrm{G}^{0}\right)$, the standard change in entropy $\left(\Delta \mathrm{S}^{0}\right)$ and the standard change in enthalpy $\left(\Delta \mathrm{H}^{0}\right)$. The relation between $\Delta \mathrm{G}^{0}, \Delta \mathrm{S}^{0}$ and $\Delta \mathrm{H}^{0}$ is given as (Mokri , H. S. G., et al., 2015):

$$
\Delta G^{o}=\Delta H^{o}-T \Delta S^{o}
$$

The nature of the adsorption of Methylene blue on the prepared activated carbons was predicted by estimating the thermodynamic parameters. The change in thermodynamic parameters such as free energy $\left(\Delta \mathrm{G}^{0}\right)$, entropy $\left(\Delta \mathrm{S}^{0}\right)$ and enthalpy $\left(\Delta \mathrm{H}^{0}\right)$ were evaluated from the following equation (Mokri , H. S. G., et al., 2015).

$$
\Delta G^{\circ}=-R T \ln K_{C}
$$

Where, $\mathrm{K}_{\mathrm{C}}$ is the equilibrium constant and calculated as

$$
K_{C}=\frac{C_{A e}}{C_{e}}
$$

$\mathrm{C}_{\mathrm{Ae}}\left(\mathrm{mg} \mathrm{g}^{-1}\right)$ and $\mathrm{C}_{\mathrm{e}}\left(\mathrm{mg} \mathrm{L}^{-1}\right)$ are the equilibrium concentration for solute on the adsorbent and in the solution, respectively. The $\mathrm{K}_{\mathrm{C}}$ values were used to determine the $\Delta \mathrm{G}^{0}, \Delta \mathrm{S}^{0}$ and $\Delta \mathrm{H}^{0}$. The in terms of the $\Delta \mathrm{H}^{0}(\mathrm{KJ} / \mathrm{mol})$ and $\Delta \mathrm{S}^{0}(\mathrm{KJ} / \mathrm{mol} \mathrm{K})$ as a function of temperature(Mokri , H. S. G., et al., 2015).

$$
\ln K_{C}=-\frac{\Delta H^{o}}{R T}+\frac{\Delta S^{o}}{R}
$$

$\Delta \mathrm{H}^{0}$ and $\Delta \mathrm{S}^{0}$ were obtained from the slope of intercept of the plot of $\ln \mathrm{K}_{\mathrm{C}}$ against $1 / \mathrm{T}$ (Figure 5). The free energy change $\left(\Delta \mathrm{G}^{0}\right)$ indicates the degree of spontaneity of the adsorption process and the higher negative value reflects a more energetically favorable adsorption. The increase in negative value of $\Delta \mathrm{G}$ with increasing temperature show that the adsorption of $\mathrm{MB}$ on prepared $\mathrm{AC}$ sample increased with the rise in temperature. The positive values of $\Delta \mathrm{H}^{0}$ confirmed Endothermic nature of the adsorption process in the studied range $20-60{ }^{\circ} \mathrm{C}$. The positive values of $\Delta \mathrm{S}^{0}$ confirmed the randomness at the solid/solution interface during adsorption of dye on AC. The results are depicted in Table 2 (Namasivayam, C. and Kavitha, D., 2002).

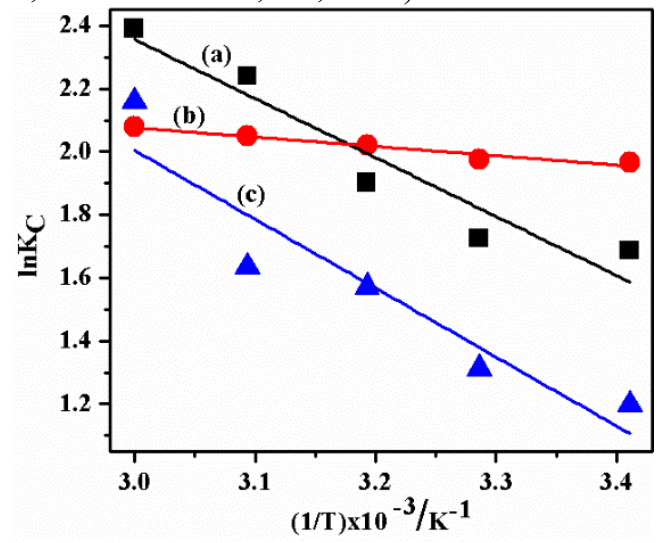

Figure 5. Van't Hoff plot for determination of thermodynamic parameter for the adsorption of MB on AC of (a) $\mathrm{EB},(\mathrm{b}) \mathrm{AA}$ and (c) ME. 
Table 2. Thermodynamic parameters for the adsorption of MB on AC of EB, AA and ME.

\begin{tabular}{|c|c|c|c|c|c|c|c|}
\hline \multirow[t]{2}{*}{ AC Type } & \multicolumn{5}{|c|}{$\Delta \mathrm{G}^{0} /\left(\mathrm{KJmol}^{-1}\right)$} & \multirow{2}{*}{$\begin{array}{l}\Delta \mathrm{H}^{0} / \\
\left(\mathrm{KJmol}^{-1}\right)\end{array}$} & \multirow{2}{*}{$\begin{array}{l}\Delta \mathrm{S}^{0} / \\
\left(\mathrm{KJmolK}^{-1}\right)\end{array}$} \\
\hline & $293 \mathrm{~K}$ & $303 \mathrm{~K}$ & $313 \mathrm{~K}$ & $323 \mathrm{~K}$ & $333 \mathrm{~K}$ & & \\
\hline EB & -4.106 & -4.3345 & -4.571 & -6.08 & -6.619 & 15.513 & 0.066 \\
\hline AA & -4.789 & -4.977 & -5.259 & -5.509 & -5.762 & 18.166 & 0.071 \\
\hline $\mathrm{ME}$ & -2.917 & $-3,304$ & -4.087 & -4.387 & -5.98 & 2.456 & 0.0246 \\
\hline
\end{tabular}

\subsection{Adsorption Equilibrium Study: Langmuir and Freundlich Isotherms}

Adsorption equilibrium is established when the amount of solute being adsorbed on to the adsorbent is equal to the amount being desorbed. The equilibrium adsorption isotherms were depicted by solid phase concentration $\left(\mathrm{q}_{\mathrm{e}}\right)$ against liquid phase concentration $\left(\mathrm{C}_{\mathrm{e}}\right)$ of solute. Adsorption isotherms are useful for finding the adsorption capacity of the adsorbent, the solute-solution interaction and the degree of accumulation of adsorbate onto the surface of adsorbent. In the present study, the adsorption of MB onto the surface of the prepared ACs was studied by two adsorption isotherm models: Langmuir and Freundlich isotherms.

The Langmuir isotherm is applicable to homogeneous sorption where the sorption of each sorbet molecule on to the surface has equal sorption activation energy. The linear form of Langmuir equation is given as (Yagub, M. T., et al., 2014):

$$
\frac{1}{q_{e}}=\left(\frac{1}{q_{m} b}\right) \frac{1}{C_{e}}+\frac{1}{q_{m}}
$$

Where, $\mathrm{q}_{\mathrm{e}}(\mathrm{mg} / \mathrm{g})$ is the amount of adsorbed MB per unit weight of adsorbent at equilibrium concentration, $\mathrm{C}_{\mathrm{e}}\left(\mathrm{mgL}^{-}\right.$ $\left.{ }^{1}\right)$. the $\mathrm{q}_{\mathrm{m}}\left(\mathrm{mg} \mathrm{g}^{-1}\right)$ and $\mathrm{b}\left(\mathrm{L} \mathrm{mg}^{-1}\right)$ are the Langmuir constant related to the maximum monolayer capacity and energy of adsorption, respectively.

The Adsorption data were analyzed according to the linear form of equation. The plots of $1 / \mathrm{q}_{\mathrm{e}}$ versus $1 / \mathrm{C}_{\mathrm{e}}$ are linear which indicates that the adsorption data fitted reasonably to the Langmuir isotherm (Figure 6(i)). The $\mathrm{q}_{\mathrm{m}}$ and $b$ were evaluated from the intercept $1 / q_{m}$ and slope $1 / q_{m} b$ respectively. The results are also summarized in Table 3.
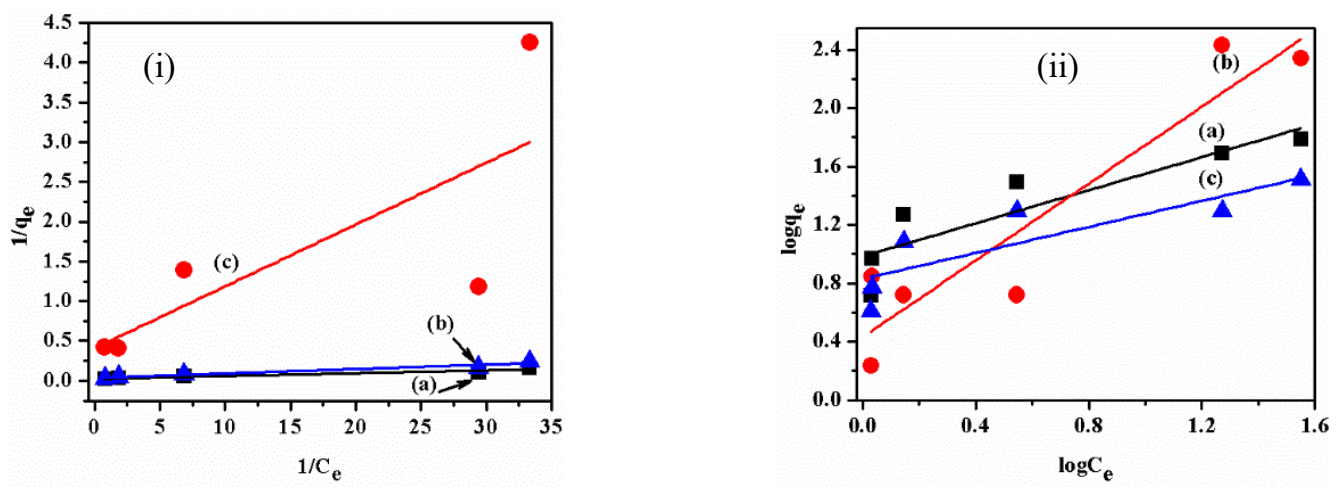

Figure 6. Adsorption isotherm study (i) Langmuir adsorption isotherm for AC of (a) EB, (b) ME and (c) AA. and (ii) Freundlich isotherm study for AC of (a) EB, (b) AA and (c) ME

The most important multisite or multilayer adsorption isotherm for heterogeneous surface is the Freundlich isotherm which is characterized by the heterogeneity factor $1 / \mathrm{n}$, and is represented by the equation (Yagub, M. T., et al., 2014):

$$
q_{e}=K_{F} C_{e}^{\frac{1}{n}}
$$

Where the $\mathrm{K}_{\mathrm{F}}$ and $1 / \mathrm{n}$ are the Freundlich constants to adsorption capacity and intensity of adsorption respectively. The isotherm is an empirical equation based on the exponential distribution of adsorption sites and energies. The linear form of Freundlich Adsorption isotherm which assumes that adsorption takes place on heterogeneous surfaces can be expressed as (Yagub, M. T., et al., 2014):

$$
\log q_{e}=\frac{1}{n} \log C_{e}+\log K_{F}
$$

Values of $\mathrm{K}_{\mathrm{F}}$ and $\mathrm{n}$ were calculated from the intercept and slope of plots of $\log \mathrm{q}_{\mathrm{e}}$ versus $\log \mathrm{C}_{\mathrm{e}}$ (Figure 6(ii)). If the value of $\mathrm{n}$ is greater than one, this indicates good adsorption of $\mathrm{MB}$ onto adsorbent. Otherwise desorption becomes predominant. If $\mathrm{n}$ equals one, the adsorption is linear. For $\mathrm{n}$ less than one, the adsorption is chemisorption, and for $\mathrm{n}$ greater than one the adsorption is favorable physical adsorption(Hameed, B.H., et al., 2011).

As we can observe from Figure 6(i), Figure 6(ii) and Table 3 adsorption of MB on EB and ME best fitted with Langmuir isotherm whereas adsorption of MB on AA fitted with Freundlich isotherm. 
Table 3. Langmuir and Freundlich Adsorption isotherm constants

\begin{tabular}{llllllll}
\hline AC Type & \multicolumn{3}{c}{ Langmuir Isotherm } & \multicolumn{4}{c}{ Freundlich Isotherm } \\
\cline { 2 - 8 } & $\mathrm{Q}_{\mathrm{O}}$ & $\mathrm{B}$ & $\mathrm{R}_{\mathrm{L}}$ & $\mathrm{R}^{2}$ & $\mathrm{~K}_{\mathrm{F}}$ & $\mathrm{n}$ & $\mathrm{R}^{2}$ \\
\hline EB & 43.66 & 6.3694 & 0.0103 & 0.91551 & 9.624 & 1.3162 & 0.75941 \\
$\mathrm{AA}$ & 2.4925 & 0.1681 & 0.349 & 0.45618 & 2.7156 & 6.7561 & 0.85247 \\
$\mathrm{ME}$ & 27.33 & 6.6028 & 0.01 & 0.92837 & 1.0838 & 2.2436 & 0.66951 \\
\hline
\end{tabular}

3.6. Adsorption Kinetic Study: Pseudo First-order and Pseudo Second-order adsorption kinetics

Kinetic models have been exploited to test the experimental data to determine the mechanism of the adsorption and its potential rate-controlling step that include mass transfer and chemical reaction. Adsorption kinetics expressed as the solute removal rate that controls the resident time of sorbet in solid-solution interface. These models include pseudo-first order and pseudo-second order models. The Lagergen pseudo first-order equation (Ahmad, M.A. and Alrozi, R., 2011, Yuh, S.H., 2004 ), is generally expressed as follows:

$$
\frac{d q_{t}}{d t}=k_{1}\left(q_{e}-q_{t}\right)
$$

Where $\mathrm{q}_{\mathrm{e}}$ and $\mathrm{q}_{\mathrm{t}}$ are amounts of dye adsorbed $\left(\mathrm{mg} \mathrm{g}^{-1}\right.$ ) on adsorbent at equilibrium and at time $\mathrm{t}$, respectively and $\mathrm{k}_{1}$ is rate constant of pseudo first order adsorption $\left(\mathrm{min}^{-1}\right)$. After integration and applying boundary conditions $\mathrm{t}=0$ and $\mathrm{t}=\mathrm{t}$ and $\mathrm{q}_{\mathrm{t}}=0$ to $\mathrm{q}_{\mathrm{t}}=\mathrm{qt}$. the integrated form becomes:

$$
\log \left(q_{e}-q_{t}\right)=\log q_{e}-\frac{k_{1}}{2.303} t
$$

The values of $\mathrm{k}_{1}$ and $\mathrm{q}_{\mathrm{e}}$ were calculated from the slopes and intercepts of $\log \left(\mathrm{q}_{\mathrm{e}}-\mathrm{q}_{\mathrm{t}}\right)$ against the $\mathrm{t}$ plots. The pseudo first order plot of MB adsorption on EB, AA and ME are shown in Figure 7(i).

The adsorption kinetics may also be calculated by a pseudo second order kinetic models (Ho, Y.S., 2006). The linearlized integral form of this model is (the Langergen pseudo- second order kinetic model) is given as:

$$
\frac{t}{q_{t}}=\frac{1}{k_{2} q_{e}{ }^{2}}+\frac{1}{q_{e}} t
$$

Where $\mathrm{k}_{2}$ is rate constant of second order adsorption $(\mathrm{g} / \mathrm{mg} / \mathrm{min})$. Slope and intercept of plot of $\mathrm{t} / \mathrm{q}_{\mathrm{t}}$ against $\mathrm{t}$, gives values of $\mathrm{q}_{\mathrm{e}}$ and $\mathrm{k}_{2}$ respectively (Figure 7(ii)). As it can be viewed in Table 4 for all the types of ACs the result showed a very good compliance with the pseudo-second order equation with high regression coefficients $\left(\mathrm{R}^{2}\right)$ compared with pseudo-first order.
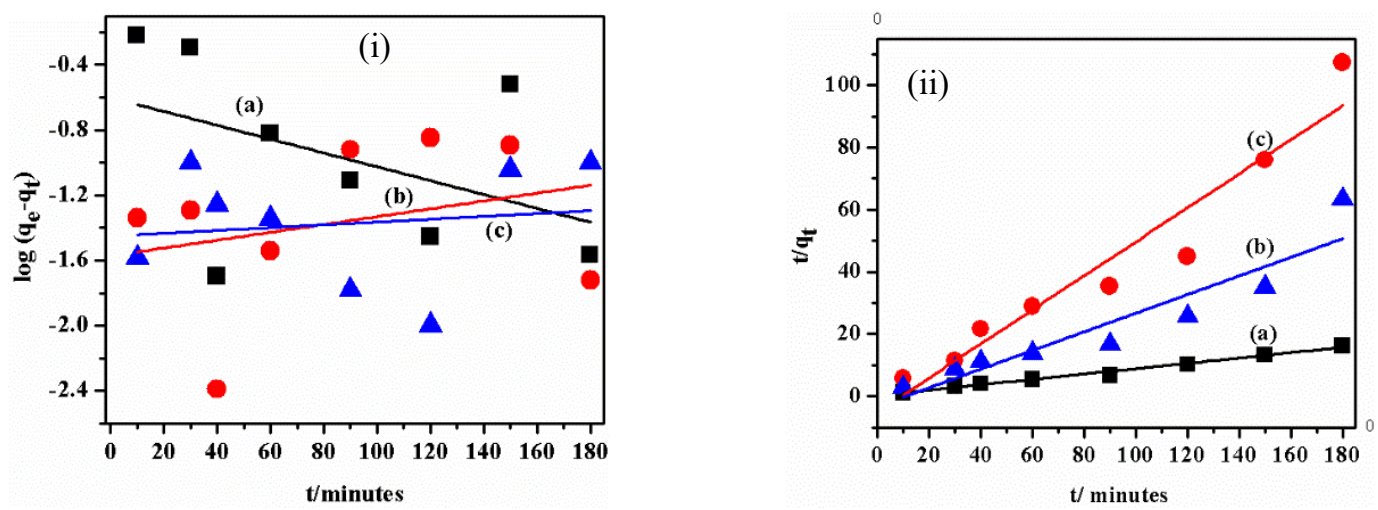

Figure 7. Adsorption Kinetic Study (i) Pseudo-First order kinetic fitting for MB adsorption onto AC of (a) EB,

(b) ME, and (c) AA. (ii) Pseudo-second order of kinetic fitting for MB adsorption onto AC of (a) EB, (b) AA and (c) ME.

Table 4. Pseudo-first and Pseudo-Second order kinetic models constants.

\begin{tabular}{lllllll}
\hline AC type & \multicolumn{5}{l}{ Pseudo-First order } & \multicolumn{4}{l}{ Pseudo-second order } \\
\cline { 2 - 7 } & $\mathrm{q}_{\mathrm{e}} / \mathrm{mg} \cdot \mathrm{g}^{-1}$ & $\mathrm{k}_{1}\left(\times 10^{-3}\right)$ & $\mathrm{R}^{2}$ & $\mathrm{qe}_{\mathrm{e}} \mathrm{mg}^{-3} \mathrm{~g}^{-1}$ & $\mathrm{k}_{2}\left(\times 10^{-3}\right)$ & $\mathrm{R}^{2}$ \\
\hline EB & 3.59 & 0.00377 & 0.13713 & 1.0163 & 0.3144 & 0.9839 \\
$\mathrm{AA}$ & 2.972 & 0.383 & 0.16661 & 3.335 & 36.19 & 0.8557 \\
$\mathrm{ME}$ & 33.7 & 0.0176 & 0.22561 & 1.0869 & 5.98 & 0.92 \\
\hline
\end{tabular}

\section{Conclusions}

Studies were conducted to investigate the potential of AC prepared from EB, AA and ME as adsorbents for the removal of $\mathrm{MB}$ from aqueous solutions. Effects of the experimental conditions on the performance of the ACs as adsorbents were studied and the adsorption data were fitted by Langmuir and Freundlich adsorption isotherm 
models. For AC of AA the result was best fitted with Freundlich model whereas for AC of EB and ME it was best fitted with Langmuir model. The result of the characterization showed that AC of EB, AA and ME have a welldeveloped surface area for adsorption. From MB number the prepared AC of EB show the highest macro porous surface area and ME show the lowest. The surface functional groups were investigated by FT-IR Spectroscopy techniques. $\mathrm{pH}_{\mathrm{pzc}}$ indicated the activated carbon have slightly basic surface functional groups. The data obtained from the adsorption isotherms at different temperatures were used to calculate thermodynamic parameters, with the results indicating that the adsorption of $\mathrm{MB}$ onto $\mathrm{AC}$ of $\mathrm{EB}, \mathrm{AA}$ and $\mathrm{ME}$ was spontaneous. A pseudo secondorder mechanism was confirmed for the adsorption kinetics. The prepared AC materials presented a great potential as an inexpensive and easily available alternative adsorbent for the removal of cationic dyes in wastewater treatments. Although tested only for $\mathrm{MB}$, one can safely assume that AC of EB, AA and ME will present similar adsorption performances for the removal of other cationic dyes from aqueous solutions.

\section{Conflicts of Interest}

The authors declare that there are no conflicts of interest regarding the publication of this paper.

\section{Acknowledgments}

This work was supported by grants from Hawassa University Office of the Vice President for Research and Technology Transfer.

\section{Reference}

Abdelwahab, O., El Nemr, A., El-Sikaily, A., Khaled, A., (2006), "Biosorption of Direct Yellow 12 from aqueous solution by marine green algae Ulva Lactuca", Chem. Ecol. 22, 253-266.

Acemioglu, B. (2004), "Adsorption of Congo red from aqueous solution onto calcium rich fly ash", Journal of colloids and interference science.,274(2),371-379.

Ahmad, M.A., Alrozi, R. (2011), "Removal of malachite green dye from aqueous solution using rambutan peelbased activated carbon: Equilibrium, kinetic and thermodynamic studies", Chemical Engineering Journal $171,510-516$

Akkaya, G., Uzun, I'., Guzel, F. (2007), "Kinetics of the adsorption of reactive dyes by chitin", Dyes Pigments 73, $168-177$.

Avom, J. Mbadcam, J.K., Noubactep, C., (1997), “Adsorption of Methylene blue from an aqueous solution on to activated carbon from palm tree cobs", Carbon., 35,365-369.

Cooper, P. (1995) Color in Dye House Effluent. Soc Dyers and Colorists, Alden Press, Oxford.

El-Sikaily, A., Khaled, A., El Nemr, A., Abdelwahab, O. (2006), "Removal of methylene blue from aqueous solution by marine green alga Ulva lactuca", Chem. Ecol. 22, 149-157.

Girgis, B.S, Yonis, S.S., Soliman, A.M. (2008), "Characterization of activated carbon from peanut hulls in relation to conditions of preparation", Materials letters., 57,164-172.

Ioannidou, O. and Zabaniotou, A. (2007), "Agricultural residues as precursors for activated carbon productionreview”, Renewable and sustainable energy reviews., 15, 1966-2005.

Hameed, B.H., Ahmad.A.L. and Latiff K.N.A. (2011), "Adsorption of basic dye on to activated carbon from rattan sawdust", Dyes and pigments. 72,143-149.

Han, R., Wang, Y., Han, P., Shi, J., Yang, J., Lu, Y. (2006), "Removal of methylene blue from aqueous solution by chaff in batch mode", J. Hazard. Mater. B, 137, 550-557.

Hashemian, S., Salari, K., Yazdi, Z. A. (2014), "Preparation of activated carbon from agricultural wastes (almond shell and orange peel) for adsorption of 2-pic from aqueous solution", J. Ind. Eng. Chem. 20, 1892-1900.

Ho, Y.S., Chiang, T.H., Hsueh, Y.M. (2005), "Removal of basic dye from aqueous solution using tree fern as a biosorbent", Process Biochem. 40, 119-124.

Ho, Y.S. (2006), "Second order kinetic model for sorption of cadmium onto tree fern, a comparison of linear and non-linear method", Water research.,40(1),119-125

Mokri, H. S. G., Modirshahla, N., Behnajady, M. A., Vahid, B. (2015), “Adsorption of C.I. Acid Red 97 dye from aqueous solution onto walnut shell: kinetics, thermodynamics parameters, isotherms", Int. J. Environ. Sci. Technol. 12,1401-1408.

Namasivayam, C., Kavitha, D. (2002), "Removal of Congo Red from water by adsorption onto activated carbon prepared from coir pith, an agricultural solid waste", Dyes and Pigments 54, 47-58.

Ncibi, M.C., Mahjoub, B., Seffen, M. (2007), "Kinetic and equilibrium studies of methylene blue biosorption by Posidonia oceanica (L.) fibres”, J. Hazard. Mater. 139, 280-285.

Ozacar, M., Engil, I'.A. S. (2005), "A kinetic study of metal complex dye sorption onto pine sawdust", Process Biochem. 40, 565-572.

Pandiarajan, A., Kamaraj, R., Vasudevan, S., Vasudevan, S. (2018), “OPAC (orange peel activated carbon) derived from waste orange peel for the adsorption of chlorophenoxyacetic acid herbicides from water: Adsorption 
isotherm, kinetic modelling and thermodynamic studies", Bioresour. Technol. 261, 329-341.

Rahman, I.A., Saad, B., Shaidan, S., Sya Rizal, E.S. (2005). "Adsorption characteristics of malachite green on activated carbon derived from rice husks produced by chemical-thermal process", Bioresour. Technol. 96, $1578-1583$.

Ratan, J. K., Kaur, M., Adiraju, B. (2018), "Synthesis of activated carbon from agricultural waste using a simple method: Characterization, parametric and isotherms study", Materials Today: Proceedings 5, 3334-3345.

Thuan, T. V., Thinh, P. V., Quynh, B. T. P., Cong, H. T., Tam, D. T. T., Thuan V. N., Bach, L. G. (2016), "Production of Activated Carbon from Sugarcane Bagasse by Chemical Activation with $\mathrm{ZnCl}_{2}$ : Preparation and Characterization Study", Res. J. Chem. Sci., 6(5), 42-47.

Vadivelan, V.,. Kumar, K.V (2005), "Equilibrium, kinetics, mechanism, and process design for the sorption of methylene blue onto rice husk", J. Colloid Interface Sci. 286, 90-100.

Yagub, M. T., Sen, T. K., Afroze, S., Ang, H.M. (2014), "Dye and its removal from aqueous solution by adsorption: A review", Advances in Colloid and Interface Science 209, 172-184.

Yuh, S.H. (2004), "Citation review of Langergren kinetic rate equation on adsorption reactions", Scientometrics., $59,171-177$ 